\title{
Studi Literature Optimasi Waktu dan Biaya pada Proyek Perangkat Lunak
}

Time and Cost Optimization Literature Study on Software Projects

Rizky Parlika ${ }^{1}$, Dewi Azizah ${ }^{2}$, Sarirotul Latifah*3, Benny Danendra Hadi ${ }^{4}$

${ }^{1,2,3,4}$ Universitas Pembangunan Nasional "VETERAN" Jawa Timur

e-mail: ${ }^{1}$ rizkyparlika.if@upnjatim.ac.id, ${ }^{2}$ aquazizah8@gmail.com, ${ }^{* 3}$ laateefah@gmail.com,

bennydanendrahadi@gmail.com

\begin{abstract}
Abstrak - Dalam pelaksanaan sebuah proyek perangkat lunak pasti membutuhkan usaha yang lebih untuk dapat dikatakan sebuah proyek tersebut berhasil, yaitu agar pekerjaan lebih efektif dan lebih efisien dengan sumber daya yang ada serta menghasilkan output yang baik. Seperti halnya membutuhkan optimasi waktu dan optimasi biaya minimum, masalah inilah yang sering terjadi pada pelaksanaan sebuah proyek terutama perangkat lunak karena adanya beberapa faktor seperti keterbatasan sumber daya. Oleh karena itu, Makalah ini menulis tentang penggunaan beberapa metode untuk optimasi waktu dan optimasi biaya minimum pada proyek perangkat lunak. Disini penulis membandingkan tiga metode yaitu metode CPM (Critical Path Methode), metode PERT (Program Evalution and Review Technique), dan metode PDM (Precedence Diagram Method). Tujuannya adalah agar kita bisa mengetahui dari tiga metode tersebut mana yang paling baik untuk optimasi waktu, optimasi biaya minimum atau keduanya secara akurat.
\end{abstract}

Kata kunci-CPM; optimasi biaya; optimasi waktu; PDM; PERT;

\begin{abstract}
In implementing a software project, it certainly requires more effort to be able to say a project is successful, namely so that the work is more effective and more efficient with existing resources and produces good output. Just as it requires time optimization and minimum cost optimization, this problem often occurs in the implementation of a project, especially software due to several factors such as limited resources. Therefore, this paper writes about the use of several methods for time optimization and minimum cost optimization in software projects. Here the author compares three methods, namely the CPM (Critical Path Method) method, the PERT (Program Evaluation and Review Technique) method, and the PDM (Precedence Diagram Method) method. The goal is that we can find out which of the three methods is best for time optimization, minimum cost optimization or both accurately.
\end{abstract}

\section{Keywords - CPM; cost optimization; time optimization; PDM; PERT;}

\section{Pendahuluan}

Proyek merupakan pekerjaan kombinasi dari berbagai sumber daya dalam satu organisasi agar memenuhi tujuannya dengan proses yang berjalan dengan tegas, disiplin dan cermat[1]. Sebuah proyek juga disebut sebagai upaya sementara yang dirancang untuk menghasilkan produk yang unik dan biasanya dibatasi oleh pendanaan[2]. Perencanaan adalah kegiatan yang dilakukan dalam proyek dengan menetapkan tujuan dan sasaran yang akan dicapai dengan melihat kondisi yang ada selama proyek masih berjalan. Menurut KBBI Optimasi merupakan upaya atau cara untuk memperoleh hasil yang terbaik. Sedangkan, perangkat lunak menurut KBBI merupakan perangkat program, prosedur dan dokumen yang berkaitan dengan suatu sistem (misalnya sistem komputer). Jadi, optimasi perangkat lunak adalah upaya memenuhi tujuan kegiatan di bidang perangkat lunak dengan menetapkan sasaran dan melihat kondisi selama proyek berjalan[3]. Dimana keberhasilan penjadwalan proyek adalah faktor kunci sukses proyek itu berhasil. Terkait biaya yang rendah 
pada pengembangan perangkat lunak pada manajemen proyek selalu menjadi prioritas banyak organisasi terutama dengan waktu yang terbatas[4].

Namun dari sekian banyak proyek perangkat lunak, kendala yang sering terjadi yaitu terkait waktu dan biaya dikarenakan berbagai faktor seperti sumber daya yang terbatas atau timeline dari konsumen yang kurang toleransi[5][6][7].

Maka dari itu, pada makalah ini kita akan merangkum beberapa metode dalam optimasi waktu dan optimasi biaya proyek perangkat lunak. Adapun beberapa metode tersebut, yaitu, metode CPM (Critical Path Method), metode PERT (Program Evalution and Review Technique), dan metode PDM (Precedence Diagram Method).

\section{LANDASAN TEORI}

\section{II.I.CPM (Critical Path Method)}

CPM yaitu suatu metode yang digunakan dengan menentukan jalur kritis dan melakukan percepatan dengan menggunakan Crash Program. Metode CPM merupakan salah satu metode yang digunakan untuk keseimbangan waktu-biaya linier[8] atau bisa disebut untuk menyelesaikan optimasi waktu dan biaya pada suatu perencanaan[9]. Maka dari itu, penerapan CPM bermanfaat dalam displin perencanaan dan penjadwalan proyek. Setiap pekerjan bisa diselesaikan dengan cepat dari waktu normalnya karena adanya pintasan biaya tertentu, jika waktu penyelesaiannya tidak memuaskan maka dapat dipintaskan dengan waktu yang lebih sedikit[10]. Cpm banyak digunakan selain sifatnya yang deterministik, kelebihan lain dari CPM adalah bagan waktu dapat dikonversikan dengan mudah dalam pelaksaan proyek serta jadwal yang dihasilkan beorientasi pada waktu. Namun kekurangannya faktor biaya proyek perharinya tidak diperhitungkan dalam pembuatan jadwal dan metode ini masih menggunakan batasan waktu sehingga metode ini masih memerlukan pengembangan batasan sumber daya lain.

\section{II.II. Metode PERT (Program Evalution and} Review Technique)

Seperti namanya Metode PERT adalah metode menilai dan meninjau kembali program yang bertujuan untuk sebanyak mungkin mengurangi adanya penundaan, maupun gangguan produksi, serta mengkoordinasikan berbagai bagian suatu pekerjaan secara menyeluruh dan mempercepat selesainya proyek dimana waktu merupakan dasar penting dari PERT dalam penyelesaiannya[11]. Penerapan metode ini memerlukan tiga dugaan waktu untuk setiap pekerjaan dari suatu proyek. Adapun kelebihan dari metode ini adalah mengoptimalkan waktu penyelesaian proyek, namun kekurangannya belum menekankan soal minimalisasi[12].

II.III. Metode PDM (Precedence Diagram
Method)
Metode PDM adalah metode penjadwalan proyek yang umumnya divisualisasikan dalam bentuk segi empat yang didalamnya ada node. Dimana node tersebut merupakan kegiatankegiatan yang saling berkaitan dan dihubungkan dengan symbol anak panah[13]. Adapun model penjadwalan proyek ini dapat menunjukkan hubungan keterkaitannya yang sangat jelas dan spesifik[14]. adanya percepatan waktu agar optimasi waktu terealisasikan dengan metode ini maka pekerjaan dimulai ketika pekerjaan sebelumnya belum terselesaikan misalnya, A adalah pekerjan pertama dan B adalah pekerjaan kedua dimana B dikerjakan ketika A belum terselesaikan.

\section{Metodologi}

Bab ini berisi informasi teknis dari penelitian yang disajikan secara jelas, Gambar 1 merupakan flowchart bagaiman alur paper yang penulis analisa agar mudah memahami isi paper.

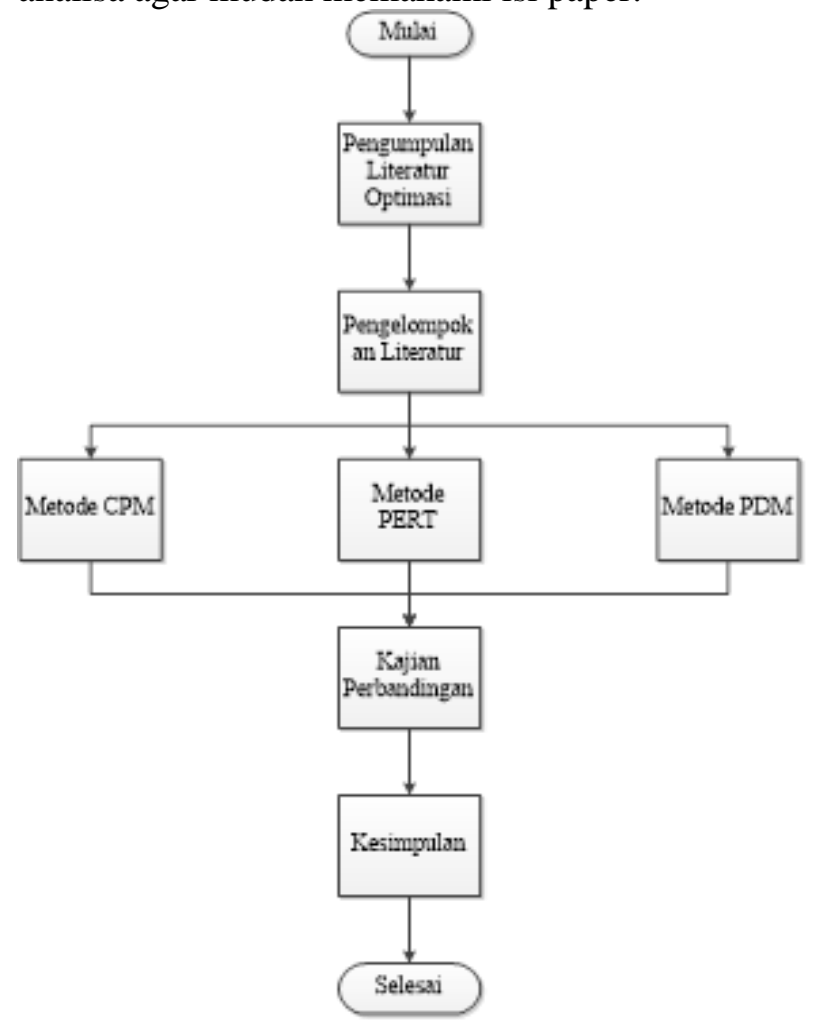

Gambar 1. Flowchart Alur Paper 


\section{III.I. CPM (Critical Path Method)}

Untuk memenuhi analisis CPM, maka terdapat dua jenis sumber data yang dibutuhkan, antara lain :

a. Data Primer, yaitu data yang diperoleh langsung dari objek yang diteletih.

b. Data Sekunder, yaitu data yang diperoleh dari sumber lembaga atau literature lain[15].

Teknik pengumpulan data yaitu melalui observasi, wawancara, studi pustaka.

Sedangkan teknis analisis data sendiri dapat diketahui dengan cara :

1. Mendeskripsikan urutan aktivitas yang dikerjakan.

2. Membuat diagram jaringan dari rangkaian aktivitas.

3. Menggunakan jalur kritis menggunakan pendekatan AON pada diagram Gantt dimana anak panah merupakan kegiatan.

4. Menetukan waktu tersibuk menggunakan metode Gantt Chart, yaitu sebagai berikut :

a. Mengidentifikasi tugas yang perlu diselesaikan misal menentugas tugas dengan menggunakan flowchat, mengidentifikasi waktu yang diperlukan, serta mengidentifikasi urutan pekerjaan tugas yang belum selesai sebelum memulai tugas baru atau tugas yang harus dikerjakan secara bersamaan.

b. Menggambarkan waktu pada tugas-tugas objek yang ditelitih secara horizontal dengan skala yang sesuai misalnya setiap hari minggu maupun bulan.

c. Menulis tugas atau bagian pekerjaan yang akan dikerjakan menurut urutan waktu.

d. Melakukan pemeriksaan ulang agar tugas atau bagian pekerjaan tidak ada yang terlewatkan dalam Giantt Chart[16].

\section{III.II. Metode PERT}

Seperti yang dijelaskan pada bab II, diagram gambar penerapan seperti pada gambar 2 dimana anak panah menunjukkan tata urutan kegiatan dalam proyek[17]. Dan Maksud dari tiga dugaan waktu tersebut, yaitu :

a. Waktu optimis (a), yaitu jika semua pekerjaan berjalan dengan baik tanpa hambatan-hambatan.

b. Waktu paling mungkin (m), yaitu akan terjadi jika suatu pekerjaan dilakukan secara normal, dengan beberapa kendala yang dapat diterima atau masih bisa ditangani atau dengan resiko yang sangat kecil.

c. Waktu pesimis (b), jika suatu pekerjaan berjalan terjadi kendala yang melebihi batas kewajaran[18]

Setelah data waktu didapat menurut tiga dugaan waktu diatas, lalu dicari nilai te (waktu yang diharapkan) dengan rumus :

$$
\text { te }=\frac{a+4 m+b}{6}
$$

Dimana :

$\mathrm{Te}=$ Waktu yg diharapkan

a $\quad=$ Waktu optimis

$\mathrm{b} \quad=$ Waktu pesimis

$\mathrm{m} \quad=$ Waktu paling mungkin

tiga dugaan waktu diatas bisa disebut juga dengan tiga estimasi waktu nilai, dimana waktu optimistik merupakan durasi terpendek, waktu paing merupan durasi rata-rata, dan waktu pesimis merupakan waktu terpanjang.

\section{III.III. Medote PDM}

Kegiatan yang mengilustrasikan segi empat karena letak kegiatan ada dibagian note maka metode PDM sering disebut AON (Activity On Node).

Jenis-jenis kegiatan PDM, yaitu :

- ES, Earliest Start

- EF, Earliest Finish

- LS, Latest Start

- LF, Latest Finish

Jenis-jenis diatas dapat dilakukan dengan perhitungan maju dan mundur[19]. Gambar 3 adalah alur perhitungan maju dan gambar 4 adalah alur perhitungan mundur.

Setelah mengetahui ES, EF, LS, LF dari setiap pekerjaan, maka langkah selanjutnya menentukan jalur kritis yang dirangkum dalam penulisan matematika, yaitu :

\section{$\mathbf{L F}-\mathbf{E S} \leq$ DA}

Jadi, jika hasil pengurangan LF dan ES pada kegiatan lebih besar daripada Dugaan Awal (DA) maka kegiatan tersebut tidak termasuk lintasan kritis atau dapat diartikan dengan tetap menggunakan Dugaan Awal karena lebih efektif[20]. 


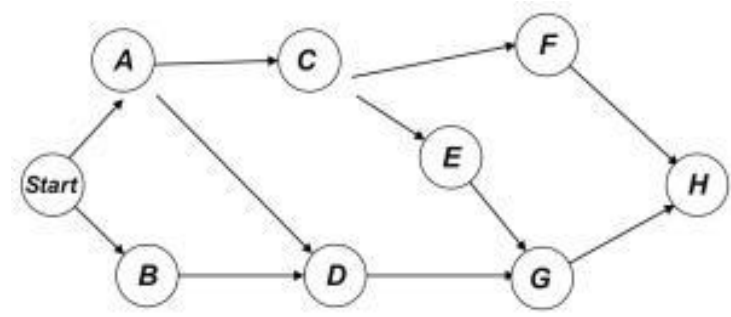

Gambar 2. Diagram Alir Metode Pert

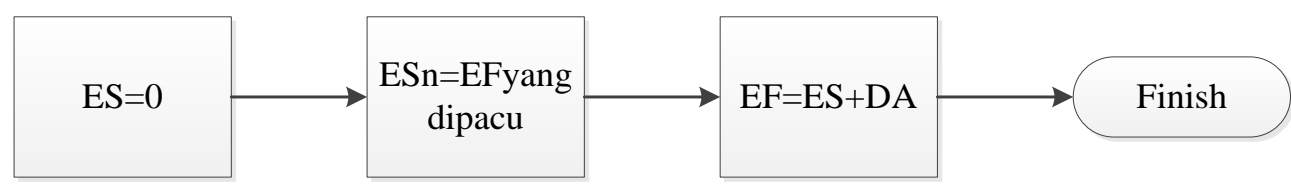

Gambar 3. Alur Perhitungan Maju

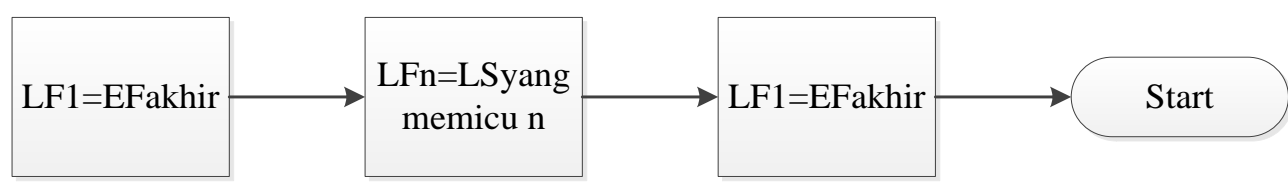

Gambar 4. Alur Perhitungan Mundur

\section{HASIL DAN PEMBAHASAN}

Dalam bab pembahasan dari ketiga metode

Dalam penerapan pendekatan dan Analisa ini kami membuat tabel untuk membantu membandingkan setiap metode tersebut.

optimasi pada Bab III adalah melakukan Analisa dan pendekatan terhadap kegiatan metode optimasi tersebut dengan cara membandingkan metode-metode optimasi pada makalah ini untuk mencari :

1. Perbedaan penerapan dari metodemetode optimasi

2. Kekurangan dan kelebihan dari setiap metode optimasi.

Tabel 1. Tabel Perbandingan Metode Optimasi

\begin{tabular}{cl}
\hline Model & \multicolumn{1}{c}{ Penerapan } \\
\hline CPM & $\begin{array}{l}\text { Menyelesaikan berbagai tahap suatu proyek yang dianggap diketahui } \\
\text { dengan pasti, demikian pula hubungan antara sumber daya yang digunakan, } \\
\text { biaya dan waktu yang diperlukan[26]. }\end{array}$ \\
\hline PERT & $\begin{array}{l}\text { PERT menggunakan pendekatan yang menganggap bahwa kurun waktu } \\
\text { kegiatan tergantung pada banyak faktor dan variasi[27], sehingga lebih baik } \\
\text { diberi perkiraan menggunakan tiga angka estimasi. PERT dan CPM } \\
\text { dihitung dengan metode yang sama, namun bedanya hanya pada PERT } \\
\text { yang menggunakan tiga prediksi waktu[28]. }\end{array}$ \\
\hline
\end{tabular}




\begin{tabular}{|c|c|}
\hline Model & Penerapan \\
\hline PDM & $\begin{array}{l}\text { Kegiatan dan peristiwa pada PDM ditulis dalam node yang berbentuk kotak } \\
\text { segiempat. Dalam PDM, kotak tersebut menandai suatu kegiatan, dengan } \\
\text { demikian harus dicantumkan identitas kegiatan dan kurun waktunya. Setiap } \\
\text { node mempunyai dua peristiwa yaitu peristiwa awal dan peristiwa } \\
\text { akhir[29]. }\end{array}$ \\
\hline
\end{tabular}

Dalam analisis kami di dalam makalah ini, tiga model penerapannya sama-sama menggunakan pendekatan AON (Activity On Node)[30] karena penerapannya mengilustrasikan diagram dimana terdapat note dan anak pah yang mempunyai arti kegunaan tersendiri.

Tabel 2. Tabel Perbedaan Metode

\begin{tabular}{|c|c|c|c|}
\hline Model & Optimasi & Kelebihan & Kekurangan \\
\hline \multirow[t]{2}{*}{ CPM } & Waktu & $\begin{array}{lr}\text { Pengoordiniran } & \text { tugas } \\
\text { waktu proyek } & \text { menjadi } \\
\text { mudah dan urut. } & \end{array}$ & $\begin{array}{l}\text { Pengumpulan data terlalu lama } \\
\text { dikarenakan harus dari sumber } \\
\text { wawancara dan observasi. }\end{array}$ \\
\hline & Biaya & $\begin{array}{l}\text { Hasil keakuratan dan } \\
\text { minimum biaya masih } \\
\text { bisa membatu dalam } \\
\text { pengoptimasian proyek. }\end{array}$ & $\begin{array}{l}\text { Butuh waktu lama untuk observasi } \\
\text { agar mencapai keakuratan minimum } \\
\text { biaya[21]. }\end{array}$ \\
\hline \multirow[t]{2}{*}{ PERT } & Waktu & $\begin{array}{l}\text { Mengoptimalkan waktu } \\
\text { penyelesaian proyek } \\
\text { dengan diagram membuat } \\
\text { mudah memahami dan } \\
\text { menjadikan target waktu } \\
\text { yang jelas[22]. }\end{array}$ & $\begin{array}{l}\text { Perkiraan atas waktu bisa } \\
\text { membutuhkan waktu yang lama } \\
\text { karena pada metode ini menggunakan } \\
\text { tiga prediksi waktu. }\end{array}$ \\
\hline & Biaya & $\begin{array}{l}\text { Minimum biaya masih } \\
\text { bisa membatu dalam } \\
\text { pengoptimasian proyek. }\end{array}$ & $\begin{array}{l}\text { Hasil pengoptimasiannya masih } \\
\text { subjektif. }\end{array}$ \\
\hline
\end{tabular}




\begin{tabular}{|c|c|c|c|}
\hline Model & Optimasi & Kelebihan & Kekurangan \\
\hline PDM & Waktu & $\begin{array}{lr}\text { Penggunaan node } & \text { dan } \\
\text { anak panah membuat } & \text { mudah } \\
\text { penjadwalan } & \text { jelas } \\
\text { dipahami dan } & \text { node } \\
\text { dimana hubungan } & \text { noling } \\
\text { dan panah } & \text { saling } \\
\text { bergantungan[23]. }\end{array}$ & $\begin{array}{l}\text { Dengan penerapannya yang bisa } \\
\text { mempekerjakan pekerjaan sebelum } \\
\text { pekerjaan sebelumnya selesai, } \\
\text { mengakibatkan banyak data yang } \\
\text { tidak dimasukkan } \\
\text { perhitungan[24]. }\end{array}$ \\
\hline
\end{tabular}

$\begin{array}{llll}\text { Biaya } & \text { Keakuratan dan minimum } & \text { Rawannya perhitungan yang blm } \\ & \text { biaya cukup bisa menyeluruh. } \\ & \text { membatu dalam } \\ & \text { pengoptimasian } & & \\ & \text { proyek[25]. }\end{array}$

\section{Kesimpulan}

Dari penjelasan diatas dapat disimpulkan bahwa metode yang bagus untuk optimasi waktu adalah metode CPM dan metode PERT, dan metode PDM masih cukup bisa membantu dalam optimasi biaya minimum. Untuk menentukan optimasi waktu dan biaya menggunakan metode PDM.

Dari penjelasan diatas dapat dilihat bahwa sistem perancangan penjadwalan yang kuat sangat penting untuk keberhasilan proyek. Maka dari itu, dapat disimpulkan metode CPM dapat digunakan sebagai metode untuk menghemat waktu proyek, CPM juga bisa menentukan waktu normal dan biaya normal artinya proyek bisa diselesaikan tanpa menambah sumber daya pada pekerjaan proyek. Sedangkan metode PERT menghasilkan optimasi waktu yang sangat singkat. Untuk menentukan optimasi waktu dan biaya dapat menggunakan metode PDM.

\section{DAFTAR PUSTAKA}

[1] M. L. Fioravanti et al., "Integrating project based learning and project management for software engineering teaching: An experience report," SIGCSE 2018 - Proc. 49th ACM Tech. Symp. Comput. Sci. Educ., vol. 2018-Janua, no. Icmc, pp. 806-811, 2018, doi: $10.1145 / 3159450.3159599$.
[2] S. Lutaaya, "Project Management Theory and Software Development Project," no. March, 2019, doi: 10.13140/RG.2.2.24335.84647.

[3] B. Farhang Moghaddam, "Mapping optimization techniques in project management," J. Proj. Manag., 2019, doi: 10.5267/j.jpm.2019.3.003.

[4] M. Niazi, S. Mahmood, M. Alshayeb, A. M. Qureshi, K. Faisal, and N. Cerpa, "Toward successful project management in global software development," Int. J. Proj. Manag., 2016, doi: 10.1016/j.ijproman.2016.08.008.

[5] P. Pospieszny, B. Czarnacka-chrobot, and A. Kobylinski, "An effective approach for software project effort and duration estimation with machine learning algorithms The Journal of Systems and Software An effective approach for software project effort and duration estimation with machine learning algorithms," J. Syst. Softw., vol. 137, no. November, pp. 184-196, 2017, doi: 10.1016/j.jss.2017.11.066.

[6] W. Zheng, Y. Qin, E. Bugingo, D. Zhang, and J. Chen, "Cost optimization for deadline-aware scheduling of big-data processing jobs on clouds," Futur. Gener. Comput. Syst., vol. 82, pp. 244-255, 2018, doi: 10.1016/j.future.2017.12.004.

[7] E. N. Alkhanak, S. P. Lee, R. Rezaei, and 
R. M. Parizi, "Cost optimization approaches for scientific workflow scheduling in cloud and grid computing: A review, classifications, and open issues," J. Syst. Softw., vol. 113, pp. 1-26, 2016, doi: 10.1016/j.jss.2015.11.023.

[8] M. Lu, J. Liu, and W. Ji, "Formalizing a path-float-based approach to determine and interpret total float in project scheduling analysis," Int. J. Constr. Manag., vol. 17, no. 4, pp. 251-263, 2017 , doi: 10.1080/15623599.2016.1207366.

[9] Y. A. Effendi and R. Sarno, "Non-linear optimization of critical path method," in Proceeding - 2017 3rd International Conference on Science in Information Technology: Theory and Application of IT for Education, Industry and Society in Big Data Era, ICSITech 2017, 2017, doi: 10.1109/ICSITech.2017.8257091.

[10] D. Pimchangthong and V. Boonjing, "Effects of Risk Management Practices on IT Project Success," Manag. Prod. Eng. Rev., vol. 8, no. 1, pp. 30-37, 2017, doi: 10.1515/mper-2017-0004.

[11] G. I. Budiawati and R. Sarno, "Time and cost optimization of business process RMA using PERT and goal programming," Telkomnika (Telecommunication Comput. Electron. Control., vol. 17, no. 2, pp. 781-787, 2019, doi: 10.12928/TELKOMNIKA.v17i2.11792.

[12] A. M. Fahmy, "Optimization Algorithms in Project Scheduling," in Optimization Algorithms - Methods and Applications, 2016.

[13] Y. He, C. Gu, Z. Chen, and X. Han, "Integrated predictive maintenance strategy for manufacturing systems by combining quality control and mission reliability analysis," Int. J. Prod. Res., vol. 55, no. 19, pp. 5841-5862, 2017, doi: 10.1080/00207543.2017.1346843.

[14] A. Atef, I. El-henawy, and M. AbdelBaset, "Project Scheduling: Survey and Research Potentials," Int. J. Comput. Appl. Technol. Res., 2015, doi: 10.7753/ijcatr0404.1005.

[15] S. Atin and R. Lubis, "Implementation of Critical Path Method in Project Planning and Scheduling," in IOP Conference Series: Materials Science and Engineering, 2019, doi: 10.1088/1757-
899X/662/2/022031.

[16] M. Sajad, M. Sadiq, K. Naveed, and M. S. Iqbal, "Software Project Management: Tools assessment , Comparison and suggestions for future development .," Int. J. Comput. Sci. Netw. Secur., 2016.

[17] D. M. Informatika, F. Teknik, and U. N. Surabaya, "PENGEMBANGAN SISTEM PENJADWALAN MATA PELAJARAN BERBASIS WEB ( STUDI KASUS : MAN SURABAYA ) Rahma Azmi Aziz Abstrak."

[18] F. Habibi, O. Taghipour Birgani, H. Koppelaar, and S. Radenović, "Using fuzzy logic to improve the project time and cost estimation based on Project Evaluation and Review Technique (PERT)," J. Proj. Manag., vol. 3, pp. 183-196, 2018, doi: 10.5267/j.jpm.2018.4.002.

[19] R. G. Solís-Carcaño, G. A. CoronaSuárez, and A. J. García-Ibarra, "The Use of Project Time Management Processes and the Schedule Performance of Construction Projects in Mexico," $J$. Constr. Eng., 2015, doi: 10.1155/2015/868479.

[20] R. Nafkha and A. Wiliński, "THE CRITICAL PATH METHOD IN ESTIMATING PROJECT DURATION," 2016.

[21] N. T. Nguyen, Q. T. Huynh, and T. H. G. $\mathrm{Vu}$, "A Bayesian critical path method for managing common risks in software project scheduling," ACM Int. Conf. Proceeding Ser., pp. 382-388, 2018, doi: 10.1145/3287921.3287962.

[22] M. K. Chin, S. L. Kek, S. Y. Sim, and T. W. Seow, "Probabilistic Completion Time in Project Scheduling," Int. J. Eng. Res. Sci., vol. 3, no. 4, pp. 2395-6992, 2017.

[23] W. Srisungnoen and W. Vatanawood, "An ontology-based knowledge acquisition for PDM," Proc. - 2018 IEEE/ACIS 19th Int. Conf. Softw. Eng. Artif. Intell. Netw. Parallel/Distributed Comput. SNPD 2018, pp. 287-292, 2018, doi: 10.1109/SNPD.2018.8441117.

[24] S. Isaac and M. Hajdu, "The Possibilities for Better Project Tracking based on the New Developments of the Precedence Diagramming Method," Procedia Eng., vol. 164, no. June, pp. 75-81, 2016, doi: 10.1016/j.proeng.2016.11.594.

[25] S. Azi Laga and R. Sarno, "Time and Cost 
Optimization Using Goal Programming and Priority Scheduling," Proc. - 2018 Int. Semin. Appl. Technol. Inf. Commun. Creat. Technol. Hum. Life, iSemantic 2018, pp. 35-40, 2018, doi: 10.1109/ISEMANTIC.2018.8549802.

[26] P. L. Guida and G. Sacco, "A method for project schedule delay analysis," Comput. Ind. Eng., vol. 128, no. December 2018, pp. 346-357, 2019, doi: 10.1016/j.cie.2018.12.046.

[27] A. Aribisala, A. Otenaike, O. Balogun, and L. Ofusori, "Analysis of an Engineering Project Using Program Evaluation and Review Technique," FUOYE J. Eng. Technol., vol. 2, no. 1, pp. 9-12, 2017.

[28] M. H. CALP and M. A. AKCAYOL, "Optimization of Project Scheduling Activities in Dynamic CPM and PERT Networks Using Genetic Algorithms," Süleyman Demirel Üniversitesi Fen Bilim. Enstitüsü Derg., 2018, doi: 10.19113/sdufbed.35437.

[29] W. Srisungnoen and W. Vatanawood, "Dependency types validation of precedence diagram method using ontology," Eng. J., vol. 22, no. 5, pp. 155-169, 2018, doi: 10.4186/ej.2018.22.5.155.

[30] H. A. Baits, I. A. Puspita, and A. F. Bay, "Combination of program evaluation and review technique (PERT) and critical path method (CPM) for project schedule development," Int. J. Integr. Eng., vol. 12, no. 3, pp. 68-75, 2020, doi: 10.30880/ijie.2020.12.03.009. 